\title{
Incentives for dishonesty: An experimental study with internal auditors
}

Loukas Balafoutas, Simon Czermak, Marc Eulerich, Helena Fornwagner

Working Papers in Economics and Statistics 2017-06 


\section{University of Innsbruck \\ Working Papers in Economics and Statistics}

The series is jointly edited and published by

- Department of Banking and Finance

- Department of Economics

- Department of Public Finance

- Department of Statistics

Contact address of the editor:

Research platform "Empirical and Experimental Economics" University of Innsbruck

Universitaetsstrasse 15

A-6020 Innsbruck

Austria

Tel: $\quad+435125077171$

Fax: $\quad+435125072970$

E-mail: eeecon@uibk.ac.at

The most recent version of all working papers can be downloaded at http://eeecon.uibk.ac.at/wopec/

For a list of recent papers see the backpages of this paper. 


\title{
Incentives for dishonesty: An experimental study with internal auditors ${ }^{\#}$
}

\author{
Loukas Balafoutas (University of Innsbruck) \\ Simon Czermak (Management Center Innsbruck) \\ Marc Eulerich (University of Duisburg-Essen) \\ Helena Fornwagner (University of Innsbruck)
}

\begin{abstract}
This study examines experimentally how dishonest behavior in the form of misreporting others' performance depends on the nature of provided incentives. We conduct a 'lab in the field' experiment with internal auditors during two large conferences in Germany and evaluate their performance and objectivity, measured as the extent to which they truthfully report the performance of other participants in a real-effort task. It has been suggested in the literature that incentive-pay compensation for auditors has the potential to lead to dishonest behavior on their part, for instance when their payoff depends on the performance of the unit that they are auditing. We vary incentives in the experiment from individual (piece rate) to competitive (tournament against another auditor) and collective (based on performance within a team). In line with our hypotheses, we find that incentive-based compensation increases dishonest behavior among internal auditors: competitive incentives lead to under-reporting of other participants' performance, while collective incentives lead to over-reporting of performance.
\end{abstract}

Keywords: dishonesty; incentives; sabotage; internal audit; experiment

JEL classifications: C93; M42; M52

This version: 20 April 2017

\footnotetext{
\# We are grateful to the German Institute of Internal Auditors (DIIR) for supporting this research project. We would like to thank our research assistants Joel Behrend, Selina Fröhle, Lisa Hauf, Ronja Krane, Sarah Stuefer and Matthias Walter for their valuable help in conducting the experimental sessions in Munich and Frankfurt. We also thank participants at the ESA European meeting 2016 in Bergen and Asia Pacific meeting 2017 in Taipei, and seminar participants at the University of Queensland, Queensland University of Technology, Max Planck Institute for Tax Law and Public Finance, GATE Lyon and the University of Innsbruck for useful comments. This project has received a Certificate of Good Standing (21/2016) from the Board for Ethical Questions in Science at the University of Insbruck.
} 


\section{Introduction}

Honest and ethical behavior within organizations is of paramount importance, not only for the organizations involved but also for stakeholders and society as a whole. It therefore comes as no surprise that the popular press as well as the academic literature abound with stories of unethical conduct, fraud or deception and with proposed mechanisms to constrain such phenomena. One aspect of unethical conduct which has received particular attention in the literature is sabotage, defined as 'any (costly) actions that one worker takes that adversely affect the output of another' (Lazear, 1989). This definition is particularly relevant in the context of tournaments and personnel economics, because it embodies the idea that employees within an organization very often compete - implicitly or explicitly - against each other for promotions, bonuses, and the like. It has been shown that, in an environment in which workers have the opportunity to evaluate each other and hence to engage in strategic sabotage, efficiency is compromised due to a combination of output destruction through sabotage and lower performance by workers in anticipation of sabotage by others (Carpenter et al., 2010). ${ }^{1}$

Sabotage in the form of destroying, reducing or under-reporting the output of one's co-workers is not the only potential threat to ethical behavior and in particular truthful information transmission in organizations. Misreporting can also take the form of inflating one's performance, for instance when individual piece rates or targets are used to determine payments (Cadsby et al., 2010; Conrads et al., 2013). Moreover, let us consider the possibility that, in certain cases, workers may have incentives to over-report the output of their colleagues. This kind of behavior may entail severe efficiency losses, arising if the management must make decisions based on false information about the performance, risk outlook, or financial viability of various teams, units, or divisions of a firm.

The propensity of an organization's employees to engage in untruthful reporting is likely to depend on the incentives - typically in the form of incentive-based compensation provided by the management. Broadly speaking, one can distinguish between three classes of incentive schemes: (i) individual schemes, which include flat payments but can also condition one's compensation on her own performance through piece rates or target-based payments, (ii) competitive schemes, in which part of an employee's compensation depends on her performance relative to other employees using tournament-like incentives, typically within a team or organizational unit, and (iii) collective or team-based schemes, which condition part of one's payment on the performance of a group using team incentives like bonuses based on achieving team targets, or even payment schemes directly tying individual payments on the overall success of (a unit of) the organization.

In this paper we examine experimentally how cheating behavior in the form of underand over-reporting varies depending on the prevailing incentive scheme. We do this using a sample of professional internal auditors recruited during two large conferences of the German Institute for Internal Audit. We measure two main outcomes, namely the performance of participants in a simple real effort auditing task as well as their evaluation (report) on the performance of one other, randomly matched participant. We differentiate between an

\footnotetext{
${ }^{1}$ See Chowdhury and Gürtler (2015) for a recent survey on sabotage in tournaments.
} 
individual, a competitive and a collective, or team-based, payment scheme. We build on the design by Carpenter et al. (2010), which features peer evaluation and sabotage opportunities in a tournament and a piece rate environment, and we add to this design a collective payment scheme based on team performance. The novelty of our study lies mainly in the fact that we extend the literature on the incentives driving untruthful information transmission regarding others' performance to include not only sabotage in the spirit of Lazear (1989), but also in the form of strategic over-reporting of peer performance. We thus study both types of misreporting and their response to incentives in a unified setting. Moreover, our work studies these questions using a sample of professionals who are typically faced with (a combination of) the three classes of incentives outlined above and whose job consists of evaluating other units within their firm, creating ample opportunities for strategic under- or over-reporting. We will argue in the following section that this sample is particularly well suited for the examination of our research questions because incentive-based compensation and the particular performance indicators used often create misaligned incentives between auditors and higher management.

In line with our hypotheses we find that, when payments are determined on the basis of mutual evaluations and competitive incentives are present, there is substantial underreporting of the matched partner's performance: on average, reported points are $22 \%$ lower than actual points. On the contrary, we find substantial over-reporting in the presence of team incentives: reported performance is inflated by about $16 \%$ on average. These findings suggest that, even in our sample which is subject to very high honesty standards in their job, misreporting of other participants' performance is relative widespread and responds to incentives in a systematic way. We further examine the share of untruthful reports and find that those are relatively low, meaning that most participants submit truthful reports but there are those who misreport in a systematic way in order to increase their monetary payoff. Finally, we do not find support for our hypothesis that competitive or collective incentives have an adverse effect on performance, and discuss possible reasons for this.

Our work relates to various strands of the literature. We have already mentioned Carpenter et al. (2010) who have shown that competitive incentives in organizations lead to more sabotage and lower performance compared to a piece rate scheme. That competitive incentives generally increase sabotage has also been shown in Harbring and Irlenbusch (2005, 2011), while Charness et al. (2014) find increased sabotage and lower performance in tournament environments even in the absence of monetary incentives. The above studies consider sabotage in the form of peer evaluation, but tournament incentives have also been shown to increase dishonesty when individuals are asked to report their own performance: Faravelli et al. (2015) show that lying about one's own performance takes place with a higher probability in competitive (compared to non-competitive) situations and that persons with a tendency to behave dishonestly often select themselves into competitive environments. Schwieren and Weichselbaumer (2010) also find that competitive pressure increases cheating on one's performance in a task, although interestingly this applies only to low performers. Lying about one's performance has further been found to increase with the prize spread in a tournament (Conrads et al., 2014) and to be more pronounced when individual performance targets are in place (Schweitzer et al., 2004; Cadsby et al., 2010). 
The literature on team incentives is more limited, but there is enough evidence to infer that team incentives have the potential to increase dishonest behavior. For instance, Danilov et al. (2013) show that fraud by financial advisors in a credence goods context is more widespread under team than under individual incentives. Conrads et al. (2013) find that lying in the die-rolling task of Fischbacher and Föllmi-Heusi (2013) is more prevalent when participants are paired in teams of two and paid according to an equal revenue-sharing rule and Wiltermouth (2011) reports a similar pattern in a word unscrambling task. Conrads et al. (2013) discuss possible reasons for this result, which is to some extent counter-intuitive because individual monetary incentives for cheating are weaker under team than under individual incentives. One possible reason, for which the authors find support, is that under team incentives there is some diffusion of responsibility since payments are determined by the sum of individual reports. Another possible reason is that misreporting in this environment benefits not only the player who gives the report, but also one more player: misreporting can therefore be classified as a Pareto white lie (Erat and Gneezy, 2012). To this discussion we add the possibility that unethical behavior is affected by social norms: in Gino et al. (2009) as well as in Kroher and Wolbring (2015) cheating becomes more frequent when participants have strong indication that another participant has also cheated, while in Gino et al. (2013) experimental participants are less likely to opt for a non-regulation environment where cheating is possible when the choice of environment is public. This is in line with the theory of how social norms of dishonesty can spread (Cialdini et al., 1990; Keizer et al., 2008). ${ }^{2}$

On a more general level, investigating behavior in connection with misreporting and sabotage focuses on ethical aspects of human decision making and is also related to a recent and expanding literature on dishonesty. ${ }^{3}$ Although subjects in experiments generally act rationally when taking into account their own and others' costs and benefits from lying (Gneezy, 2005; Sutter, 2009), there is empirical research to indicate that many people do not lie (Abeler et al., 2014) or at least that they do not fully exploit possibilities to maximize profits by acting dishonestly in order to maintain a positive self-image of honest behavior (Mazar et al., 2008). In a task often used to measure dishonesty in economic experiments, participants are found to systematically over-report a die roll in order to increase their payoff, although often not to the full extent (Fischbacher and Föllmi-Heusi, 2013; Shalvi et al., 2011). Kajackaite and Gneezy (2015) argue that individuals experience a fixed rather than convex cost of lying, which would imply that - in the absence of considerations about being exposed as a liar - some participants would never lie while others would lie to the full extent. Gneezy et al. (2013) examine individual heterogeneity with respect to lying behavior and classify experimental subjects into one of eight types based on their behavior in a sender-receiver game with opportunities for lying. They report that about one third of subjects always tell the truth, $28 \%$ act in line with pure own money maximizing behavior, and $23 \%$ lie when the incentives to do so are high, but not when they are low. Finally, the study by Rosaz and

\footnotetext{
${ }^{2}$ In a similar spirit, Cohn et al. (2014) show that dishonest behavior can also be influenced by business culture. They conduct an experimental study in which they measure the honesty of employees of large, international banks. As it turns out, the probability of dishonest behavior increases when the professional identity of bankers is made salient compared to a control treatment.

${ }^{3}$ Irlenbusch and Villeval (2015) provide a comprehensive review of the economic literature on sabotage and dishonesty seen from an ethics-based approach.
} 
Villeval (2012) is related to ours since it combines the literature on performance evaluation and lying by examining the frequency of different types of lies (using the classification of Erat and Gneezy, 2012) of a supervisor about a worker's performance. Like in our study, Rosaz and Villeval (2012) find that supervisors bias their evaluations both upwards and downwards depending on the nature of economic incentives. Our setting is quite different, using a sample of professionals and placing hierarchically equal employees either in a direct winner-takes-all competition to each other or in a team. Nevertheless, it is interesting that the findings of the two studies qualitatively point towards the same direction.

The rest of the paper is structured as follows. Section 2 introduces some important aspects of internal auditing that are relevant for this study, including potential conflicts of interest and the role of incentive-based compensation schemes. Section 3 outlines the experimental design and procedures and formulates our hypotheses, while section 4 presents the findings of the experiment. Section 5 concludes.

\section{Internal auditing and auditors' objectivity}

Internal auditing is one of the main pillars of good corporate governance (IIA, 2016). The Institute of Internal Auditors (henceforth IIA), the worldwide professional association of internal auditors, defines in its professional practice framework the fundamental purpose and scope of internal auditing as follows: 'Internal auditing is an independent, objective assurance and consulting activity designed to add value and improve an organization's operations. It helps an organization accomplish its objectives by bringing a systematic, disciplined approach to evaluate and improve the effectiveness of risk management, control, and governance processes' (IIA, 2016). All internal auditors and internal audit functions who are members of the IIA or auditors who hold a professional certification of the IIA have to follow this definition and the professional practice framework. To create value for an organization through the different consulting and assurance activities, the objectivity of internal audit functions and the personal objectivity of each internal auditor is existential. The IIA specifies this attribute in the standard 1120, 'Individual Objectivity': 'Internal auditors must have an impartial, unbiased attitude and avoid any conflict of interest.' In their interpretation, the worldwide standard-setter explains that conflicts of interests may arise when an internal auditor has a competing professional or personal interest and cannot fulfill his or her duties objectively. Hence, the questions of objective reporting that we study in our experiment are essential in the field of internal audit.

One stream of research finds potential conflicts of interests if internal auditors are in companies that use internal auditing as a so-called Management Training Ground (henceforth MTG), e.g., Messier et al., 2011; Christ et al., 2015; Abbott et al., 2016. MTG describes a staffing arrangement, which rotates new or experienced employees into the internal audit functions for a certain time, before promoting them into management positions outside 
internal audit after a successful period as an internal auditor. ${ }^{4}$ Only the best and overperforming internal auditors will be promoted into promising positions, while underperforming auditors will stay for a longer period in the internal audit functions or will never get a promotion. Findings show that, especially in this arrangement, a loss of objectivity (Hoos et al., 2014; Rose et al., 2013) and efficiency (Anderson et al., 2012) can be identified.

Another potential conflict of interest closely related to our experimental design arises from the compensation of internal auditors. In general, through an incentive-based compensation individuals should be motivated to align their own interests with the interests of the company in order to minimize agency problems (Baker et al., 1988; Chong and Eggleton, 2007). However, a risk of biased measures of performance in order to maximize the individual welfare can also be recognized (Watts and Zimmermann, 1990). This type of behavior is not only dysfunctional, but also ethically questionable and not objective. In particular, incentive-based compensation can influence the objectivity and pose a threat for the professional judgement of internal auditors. Prior research has shown that incentive-based compensation is a common practice in many organizations (e.g., DeZoort et al., 2000; Dickins and O'Reilly, 2009) and that it can have an impact on internal auditors' objectivity (Schneider, 2003, Omar and Stewart, 2015). The typical types of performance indicators with influence on the individual payment are overall company performance, performance of the internal audit function, and individual performance (DeZoort et al., 2000). On the one hand, this structure should increase the productivity and motivation of auditors and recruit talented new employees. On the other hand, negative findings of an audit can decrease the company's performance and thus indirectly reduce the individual salary of an internal auditor, which can affect their objective judgement (Mutchler, 2003). Schneider (2003) argues that internal auditors' behavior is comparable to that of managers and that the decision to be objective is influenced by extrinsic rewards. Omar and Stewart (2015) show that incentive-based compensation based on company performance significantly affects internal auditors' objectivity, if the latter bias their decision to achieve a company's performance targets. They find no evidence that compensation based on individual performance influences objectivity, due to concerns about job security and the long-term career prospects of the auditor.

Both practices, incentive-based compensation and MTG, are a common practice of today's internal audit functions. For instance, with respect to incentive-based pay, a recent survey among 450 internal auditors in Germany, Austria and Switzerland reveals that more than half of the respondents had a variable component in their wage. This variable component depends primarily on the success of the firm (in $43 \%$ of cases) and on the achievement of individual targets (in $45 \%$ of cases), and to a lesser extent ( $8 \%$ of cases) on the results of the audited unit (Eulerich, 2014). As a consequence, internal auditors are in a situation where outperforming their own objectives and measures can increase their chance of moving up into a future management position and also maximize their individual wealth. It is obvious that the motivation to misreport, cheat or sabotage in reporting audit results is very high. We believe

\footnotetext{
${ }^{4}$ Internal auditing is a suitable function for this approach, because auditors perform a large range of activities across different departments within the organization and gain experiences with various parts of the business as a preparation for future positions.
} 
that this makes the setting of our experiment particularly well-suited to study the interplay between compensation schemes and (dis)honest behavior.

\section{The experiment}

\subsection{Design and experimental procedures}

We approach the issues discussed above by running a 'lab in the field' experiment with professional internal auditors who are members of the German Institute for Internal Audit ('Deutsches Institut für Interne Revision', DIIR). We take the study by Carpenter et al. (2010) as the benchmark for our design. Participants in our experiment performed a real effort task, namely the identification of incorrectly added sets of three two-digit random numbers between 11 and 99. The use of real effort tasks is widespread in economic experiments (Charness and Kuhn, 2011), and we chose this particular task because to some extent its nature (discovering errors) is related to everyday tasks and processes of our participants in their workplace.

In detail, participants received a list of 30 calculations and the information that out of 30 stated results 10 were wrong. ${ }^{5,6}$ Their task was to identify, without using a calculator, as many of the mistakes as possible within three minutes and to mark the mistaken calculations with a cross. They received one point if they correctly identified a mistake and minus 0.5 points if they marked a correct result as false. This means that the highest possible score in this task is 10 points and the lowest possible score is -10 points, while if a participant crossed out all 30 calculations she would achieve a score of zero.

All participants had to go through three stages in which they performed the task outlined above. These stages correspond to the three different types of incentives discussed in the introduction, namely individual, competitive, and team incentives. Every participant received a new sheet of calculations for each stage, but we ensured by testing the real effort tasks with students that the difficulty of the calculations remained the same for each stage. We should also point out that participants received no feedback between stages regarding the reported points, or regarding whether they had won the competition (in Stage 2, see below). Feedback was only provided when subjects were paid their earnings after the end of the experiment. The incentives for the three stages were as follows:

Stage 1: Individual incentives. Participants received a fixed payment of $€ 2$, plus a piece rate of $€ 2$ for each point they achieved in the task.

\footnotetext{
${ }^{5}$ An example sheet can be found in Figure A.1 in the Appendix.

${ }^{6} \mathrm{We}$ distributed the incorrect results across the list of calculations by always placing one incorrect calculation by chance somewhere within three consecutive calculations: for instance, this means that within the first four calculations at least one and at most two were wrong. This was not made known to participants. In addition, to avoid the possibility of some subjects identifying the mistakes very quickly by checking the sum of the last digits only, we chose the calculations such that, in every stage, only two out of the ten mistakes could be identified by looking at last digits only.
} 
Stage 2: Competitive incentives. Participants were randomly assigned into groups of two and competed against each other. The higher performer in each group (i.e., the person with the higher number of points in the task) received a fixed payment of $€ 2$ plus a payment that was double the one in the piece-rate scheme ( $€ 4$ per achieved point), while the low performer received only the fixed payment. Participants had no information regarding the identity of their partner, nor did they know that they would evaluate the performance of the same person who would evaluate them. This was done in order to minimize concerns that reporting behavior could be driven by motives of conditional reciprocity.

Stage 3: Team incentives. Participants were again in groups of two and were paid according to a simple equal sharing rule: each group member was paid the fixed payment of $€ 2$, plus $€ 1$ for each point achieved in the task by the two group members together (i.e., half the piece rate payment). Participants had no information regarding the identity of their partner and, to avoid spillovers between stages, they were told that they would be matched with a different partner than in stage 2 .

To control for order effects we let half of the participants go through the three stages in the order outlined above, while for the other half we reversed the order between the competitive and the team stage. After performing the task and handing back the answer sheet to the experimenters, each participant received a sheet from the experimenters, showing the correct answers and where the 10 mistakes lay. He or she also received the answer sheet from another person and was asked to evaluate the number of correctly solved tasks of this matched participant. ${ }^{7}$ This was done in all three stages. It was made clear to participants that they were free to report any number they wanted for the performance of their matched participant and that there were no consequences from misreporting. ${ }^{8}$

We implemented two different treatments in a between-subjects design, varying the evaluation protocol that was used to determine payment-relevant performance in the task. The two treatments were the following:

Treatment 1: Objective evaluation (henceforth Objective). In this treatment, reports made by participants about each other's performance had no consequences and all payments were based on an objective evaluation of each participant's performance by the experimenters.

Treatment 2: Peer evaluation (henceforth Peer). In this treatment, payments were solely determined on the basis of participants' reports about each other's performance.

At the end of the experiment every participant was asked to fill out a questionnaire with questions about their gender, age, level of education, working experience, working position, salary range, experience, compensation scheme, risk attitudes, and the perception of how competitive their occupation is. We ran two sessions, one in each of two large

\footnotetext{
${ }^{7}$ One possible concern could be that some participants might falsify the performance of their matched partner by changing the partner's responses ex post, in order to bring them in line with his or her report. We ruled out this possibility by handing out two different colors of pens for the performance and the reporting part in each stage. Thus, no subject could have added or subtracted points from their partner without the experimenters noticing.

${ }^{8}$ To make participants feel as unobserved as possible, we installed mobile separating walls between the seats.
} 
conferences of the DIIR, in Frankfurt (June 2016) and in Munich (October 2016). Sessions lasted for about 45 minutes and the average payment was $€ 46.15$ per participant.

\subsection{Hypotheses}

Pure own money maximizing concerns lead to the straightforward prediction of underreporting (sabotage) in the competitive stage and over-reporting in the team stage in the peer evaluation treatment. In particular, a participant whose only concern is to maximize her expected payoff would report a performance of -10 for her matched partner in the competitive stage and a performance of 10 in the team stage. In the individual stage, reports about others do not matter for own payoffs and hence any report is consistent with own money maximization. Likewise in treatment Objective, since points are objectively determined by the experimenters and reports about others have no consequences whatsoever, there is no reason to expect systematic under- or over-reporting and reports can take any value.

The evidence from existing experiments described in the introduction indicates that some people are unwilling to cheat, some people cheat to the full extent if it is in their interest to do so, while others cheat but do not exploit the full extent of misreporting opportunities. Partial cheating is consistent with theories of social or self-image concerns as well as with the existence of psychological costs of lying. Such costs of lying may stem from an inherent aversion to misrepresenting the truth through telling a lie, or they may stem from guilt feelings directed towards the affected person in line with the theory of guilt aversion (Charness and Dufwenberg, 2006; Battigalli and Dufwenberg, 2007; see also Battigalli et al., 2013, for a discussion on the role of guilt in explaining lying aversion). Regardless of the nature of the psychological costs of lying, on average we should observe at least some degree of misreporting under competitive and team incentives in treatment Peer. Accordingly, we formulate our main predictions as follows:

Hypothesis 1: In the competitive stage of treatment Peer, we expect systematic underreporting such that reported points lie below actual points on average.

Hypothesis 2: In the team stage of treatment Peer, we expect systematic overreporting such that reported points lie above actual points on average.

There is an important distinction to be made between under- and over-reporting: while the former hurts the matched partner (at least in expectation), the latter benefits both players. In the taxonomy of Erat and Gneezy (2012) this is a Pareto white lie. Moreover, if agents are motivated by guilt aversion, it is likely that they expect their matched partner to expect a high report even if this means over-reporting their score; in this case, pure monetary considerations as well as guilt aversion both work towards increasing reported points. Therefore, one might expect over-reporting to be more pronounced than under-reporting in our experiment.

Regarding actual performance, provided individuals correctly anticipate full underreporting (over-reporting) of their points by their matched partner in the competitive (team) stage, then - given a positive cost of effort - they should reduce their performance to zero. If 
they anticipate some positive probability of misreporting, or if they expect only partial misreporting, then we would still expect them to reduce their performance in these stages on average, as for instance in Carpenter et al. (2010) under competition. Here, the relevant comparison is between performance in the peer evaluation treatment (in which peer reports determine payoffs) and the objective evaluation treatment (in which payoffs are determined on the basis of actual performance).

Hypothesis 3: In the competitive as well as in the team stage, we expect actual performance to be lower in treatment Peer than in treatment Objective.

\section{Results}

\subsection{Descriptive statistics}

We begin by providing in Table 1 some background information about our participants based on the post-experimental questionnaire. The statistics are also broken down by treatment, in order to show that the two samples are comparable in terms of a number of relevant characteristics.

We ran the experiment with a total of 95 participants $^{9}, 45$ in the objective evaluation and 50 in the peer evaluation treatment. $35.5 \%$ of our sample were female (33 out of 95) and the average age was 42.4 years. Only 11 participants work for a public or non-profit company, whereas the majority holds a position in a company of the financial or non-financial private sector. In our participant pool we find primarily Certified Internal Auditors, CRMAs (Certification in Risk Management Assurance), and Certified Public Accountants. Most participants occupy higher level positions (e.g., Head of Internal Auditing), which is also reflected in the reported amount of staff which works for them $(36.17 \%$ have at least one person who is hierarchically positioned underneath them).

$<$ Table 1 about here $>$

Table 1 reveals that our sample is indeed characterized by a very high prevalence of variable payment schemes: over $75 \%$ report having a variable wage component in addition to their fixed wage. This characteristic is not significantly different between treatments. Whenever wages include a variable component, the most common indicators for this component are the auditor's personal performance (62.1\% of responses) and the success of the company they are working for $(60 \%$ of responses $) .{ }^{10}$ Moreover, a substantial share of

\footnotetext{
${ }^{9}$ We collected data for 98 people in total but had to exclude three of them: one was using a mobile phone calculator even though we kindly asked him to stop using it, and two participants left before finishing Stage 3 . All three did not receive any payment and are excluded from the analysis.

${ }^{10}$ Reported annual pre-tax wages lie over $€ 90,000$ for 39 participants, between $€ 70.000$ and $€ 90.000$ for 23 participants and below $€ 70.000$ for 19 participants, while 14 participants did not report their wage range.
} 
participants (30.8\%) report being part of the Management Training Ground scheme, which as we have discussed means that they are implicitly in a tournament against other internal auditors within their organization. This proportion does not differ significantly between treatments (see Table 1). Moreover, more than half of our subjects evaluate their profession as at least moderately competitive.

We also included a question about self-assessed risk attitudes. Specifically, we asked participants if they are generally a risk-seeking person or if they try to avoid any kind of risk. The mean reported value is 5.21 on a scale from 0 (completely risk averse) to 10 (fully risk seeking), and is not significantly different between the two treatments. Finally, we also asked participants how many other people in the room they knew personally. Only one person knew more than $20 \%$ of the present persons, while on average the reported percentage was very low at $5.5 \%$.

Table 2 summarizes the actual and reported performance and the differences between the two, for each of the three incentive schemes (stages) and in each of the two treatments (Peer treatment in panel a, Objective in panel b). We begin by analyzing reported performance and the extent of misreporting in order to test our Hypotheses 1 and 2; we then turn to actual performance in section 4.3 in order to test Hypothesis 3. We note that our two main outcomes, the extent of misreporting and actual performance, do not differ significantly between the two orders with which stages 2 and 3 were played in any of the two treatments. Therefore, in what follows we pool the two orders. Moreover, for ease of exposition, from now on we refer to Stage 2 as the environment with competitive incentives and to Stage 3 as the environment with team incentives.

\section{$<$ Table 2 about here $>$}

\subsection{Reporting decisions}

Under individual incentives, reported performance (6.07 points) and actual performance (5.96 points) in treatment Peer are very close to each other and statistically indistinguishable ( $p=0.68$, Wilcoxon signed-ranks test). Hence, participants on average report each other's performance truthfully in the absence of monetary incentives to misreport. Under competitive incentives, however, participants can increase their chances of winning the tournament by under-reporting the performance of their partner. In line with Hypothesis 1, we find that these incentives introduce a large difference of 1.3 points between actual and reported points $(5.87$ vs. $4.57, p=0.04$, Wilcoxon signed-ranks test), meaning that performance is under-reported by $22.1 \%$ on average. This pattern reverses under team incentives, where participants can increase their payoff by over-reporting the performance of their partner. In this stage we find that reported performance is on average about one point higher than actual performance, which corresponds to an increase of $16.4 \%$ ( $p=0.001$, Wilcoxon signed-ranks test). This finding supports Hypothesis 2. Comparing the difference in differences across the three stages, we can confirm that under-reporting (in the competitive stage) and over-reporting (in 
the team stage) are significantly more extensive compared to the differences observed in the individual stage ( $p=0.01, p=0.001$ respectively, Wilcoxon signed-ranks tests).

It is worth comparing actual and reported points also in treatment Objective, in which reports have no bearing on payoffs regardless of the incentive scheme in place. As expected, we find no significant difference between actual and reported points in the individual stage and in the team stage ( $p=0.63, p=0.19$ respectively, Wilcoxon signed-ranks tests). However, we do find some evidence of under-reporting in the presence of competitive incentives with reported points being slightly lower (by 0.13 points) than actual points $(p=0.06)$. While at first this seems like a puzzling result given that reports in the objective evaluation treatment do not matter for payments, it can be natural for participants to engage in some limited underreporting in order to enhance their self-image or status perception. Interestingly, Carpenter et al. (2010) and Charness et al. (2014) also find that participants engage in sabotage when they compete against each other even in the absence of material incentives to do so. They say that this kind of behavior 'could be symptomatic of a simple, maybe even unconscious or affectivelemotional, response to competition' (Carpenter et al., 2010; p. 510).

The above analysis indicates that there is on average substantial misreporting. But how widespread is such behavior among participants? Table 3 shows the number of truthful and untruthful reports by stage and treatment, while Figure 1 plots for each treatment the distribution of actual output, reported output, and differences between the two (negative differences indicate under-reporting and positive differences over-reporting).

$<$ Table 3 about here $>$

$<$ Figure 1 about here $>$

A closer look at the distribution of differences between reported and actual output reveals, at first, that most participants report truthfully independent of treatment and stage. This is also confirmed in Table 3: the share of truthful reports ranges from $70 \%$ (35 out of 50 in treatment Peer and team incentives) to $86 \%$ (46 out of 50, in treatment Peer under individual incentives). Although those participants who report untruthfully are a minority, we have already seen that they lead to statistically significant differences in mean outcomes between stages, and it also turns out to be the case that the share of untruthful reports is higher under competitive and team incentives than under individual incentives in treatment Peer. This share increases from $14 \%$ in Stage 1 (individual incentives) to $26 \%$ and $30 \%$ under competitive and team incentives, respectively (individual vs. competitive stage: $p=0.109$; individual vs. team stage: $p=0.021$; competitive vs. team stage: $p=0.77$; McNemar's tests). ${ }^{11}$

\footnotetext{
${ }^{11}$ A probit regression with untruthful reporting as the dependent variable also shows that the likelihood of misreporting is significantly higher in the competitive and team stage compared to the individual stage.
} 
In the objective treatment misreporting rates are identical under competitive and team incentives $(15.6 \%$ ), but they are significantly higher with $26.7 \%$ in the individual stage ( $p<0.001$, McNemar's test). While this finding seems surprising, we note that the twelve cases of misreporting in the individual stage are almost symmetrically split between five cases of under-reporting and seven cases of over-reporting (see Figure 1), so that - as already noted above - there is no significant difference between actual and reported performance on average in this stage. Moreover, given that reporting in treatment Objective has no consequences whatsoever for payment, it is not at all clear that cases of misreporting in this treatment should be classified as cheating and it is quite likely that at least some cases of misreporting are simply the result of lack of attention or reluctance to exert any effort in order to report the correct performance. For this reason our focus lies on misreporting in treatment Peer, in which reports determine payments.

Since we have three reporting decisions for each participant, we can identify how often - and in which stage - a person misreported the performance of his or her partner in the peer evaluation treatment. ${ }^{12}$ We begin by noting that 29 out of 50 participants reported the performance of their matched partner truthfully in all three stages. Further, we find that three participants gave a truthful report in Stage 1, but untruthful reports in Stages 2 and 3. Given the monetary incentives for dishonesty in Stages 2 and 3, these participants' behavior responds to both types of incentives in the predicted way. Five participants gave untruthful reports in Stage 2 but not in Stage 3 (all of them also reporting truthfully in Stage 1), responding to competitive but not to team incentives, while seven gave untruthful reports in Stage 3 but not in Stage 2 (all but one of them reporting truthfully in Stage 1), responding to collective but not to competitive incentives. Finally, five participants gave untruthful reports in all three stages and one participant only misreported in Stage 1.

Turning to the extent of misreporting in the peer evaluation treatment, we see in Figure 1 that only one participant resorted to full sabotage by reporting a performance of -10 for their matched partner in the competitive stage, while three participants chose to report -5 points and three chose to report 0 . All but one of these reports were untruthful (the truthful report was one of the 0 's). This pattern of incomplete cheating is in line with the experimental literature discussed in the introduction. In the case of team incentives, it appears to be the case that people had weaker reservations to cheat 'all the way': eleven participants reported a perfect performance of 10 for their matched partner, when in fact only two had achieved that score. It must be acknowledged, however, that an asymmetry exists between under- and overreporting: given an average score of approximately 6 points (pooled for Stages 2 and 3 in treatment Peer) and a range of possible reported scores between -10 and 10, there is much more room for under-reporting than for over-reporting. This can explain the presence of more outliers with very strong misreporting in the competitive than in the team stage.

In Table 4 we show the results of a regression analysis for reporting decisions (in columns 1 to 4 ) and actual performance (in columns 5 and 6). The dependent variable in the reporting regressions is the difference between reported and actual points, so that positive

\footnotetext{
${ }^{12}$ We do not report here this analysis for the objective evaluation treatment, given the irrelevance of reporting decisions for payoffs.
} 
(negative) values indicate over- (under-) reporting. The independent variables are dummy variables for the competitive and the team stage, a dummy variable for the Peer treatment, interactions between the stage and treatment dummies, as well as own performance and performance of the matched partner. In addition, specifications (2), (4) and (6) further include a number of control variables collected in the post-experimental survey, namely whether the participant is in a Management Training Ground (variable MTG), whether his or her wage includes a variable component, the salary range, gender, risk and competitive attitudes. To account for the fact that each participant performs three times and also makes three reporting decisions (one in each stage), all regressions include random effects and standard errors are clustered at the participant level.

\section{$<$ Table 4 about here $>$}

The first two specifications on reporting decisions pool data from both treatments (Objective and Peer), while in columns (3) and (4) we consider each treatment separately. All reported results confirm the insights gained from the non-parametric statistical tests. In the pooled regressions, the effects of different incentives on reporting in treatment Objective are captured by the insignificant coefficients on the competitive and the team stage. The negative coefficients on the interaction term Competitive*Peer show that the effect of competitive incentives is significantly different in treatment Peer compared to Objective, capturing the difference in differences, and the same argument applies to the positive coefficients on Team*Peer. In order to formally test the hypotheses that competitive (team) incentives lead to statistically significant under-reporting (over-reporting), we need to test the joint coefficients $($ comp + comp $x$ peer $)$ and (team + team $x$ peer $)$. F-tests on the restrictions that the joint coefficients are equal to zero yield $p<0.01$ for both restrictions in specifications (1) and (2). In the regressions broken down by treatment, we again see that reporting decisions are significantly affected by the incentive system in treatment Peer (column 4), but not in Objective (column 3). The above analysis, taken together with the non-parametric tests, allow us to formulate our first two results.

Result 1: Compared to individual incentives, competitive incentives lead to statistically significant under-reporting of other participants' performance. This supports Hypothesis 1.

Result 2: Compared to individual incentives, team incentives lead to statistically significant over-reporting of other participants' performance. This supports Hypothesis 2.

Regarding the effect of other variables, we begin by noting the coefficient on the performance of the matched partner, which is negative and significant in (1) and (2), suggesting that high performers are more likely to be the victims of sabotage. ${ }^{13}$ In columns (2) and (4) we also see a positive coefficient for own performance, meaning that high performers

\footnotetext{
${ }^{13}$ This result has been suggested in the theoretical model of Chen (2003), while Balafoutas et al. (2012) find empirical evidence to support it using field data from Judo tournaments.
} 
also report higher numbers for their matched partners, ceteris paribus. Focusing on the data from treatment Peer, which drives most of the variation in our data, two more variables are marginally significant: reported points are negatively associated with the perceived competitiveness of the internal auditing profession (indicating that participants who perceive their job environment as more competitive report lower scores for their matched partners on average), and negatively associated with wage levels.

Looking at the difference between reported and actual performance in the Table 4 regressions does not take into account the fact that, depending on the actual performance of their matched partner, some participants have smaller or larger opportunities for cheating. For instance, if my matched partner's performance is nine points, I can only over-report her performance by one point while I can under-report by up to 19 points. In the appendix (Table A.1) we report alternative versions of specifications 1 and 2 from Table 4, using relative overor under-reporting as the dependent variable, i.e., the difference between reported and actual points as a percentage of the maximum possible difference in each case. Since this new variable is left-censored at -1 and right-censored at 1 , we use the Tobit model. We confirm that Results 1 and 2 hold for this alternative specification. Moreover, comparing the effects of competitive and collective incentives in treatment Peer reveals that team incentives lead to much more misreporting than competitive incentives do once we take into account the extent of the opportunities for cheating. For instance, in the second specification, over-reporting in the team stage relative to an individual's true performance is almost $20 \%$ higher than in the individual stage, while this difference is less pronounced for under-reporting in the competitive stage and lies at around 11 percentage points.

\subsection{Performance}

We begin by comparing performance across stages in order to examine how it responds to incentives within a given treatment. Casual inspection of the means in Table 2 as well as statistical testing shows that performance does not differ across stages. This finding suggests that performance does not respond to incentives and it is in contrast to much of the literature, which generally finds that performance increases in the presence of competitive incentives. Nevertheless, this finding can be explained if participants are already investing maximum effort in Stage 1 (for instance because the costs of effort are relatively low), so that performance cannot increase any further. In general, the response of performance to monetary and non-monetary incentives in real effort tasks in economic experiments is less clear-cut as one would think, and some recent papers show that participants in experiments often do not change their performance in response to stronger incentives (Eckartz et al., 2012; Araujo et al., 2016) or that this change depends critically on the particular task used (Takahashi et al., 2016).

Our Hypothesis 3 predicts that actual performance will be lower in treatment Peer than in Objective when competitive or team incentives are present, but not under individual incentives. What we observe in the data (see Table 2) is that actual performance is indeed lower in Peer than in Objective under competitive incentives (5.87 vs. 6.66; $p=0.02$, Mann- 
Whitney test) and team incentives (6.16 vs. 7.04, $p=0.08)$, which is consistent with our prediction. However, actual performance is also lower in Stage 1 (5.96 vs. 6.73, $p=0.04$ ). The difference-in-differences is very small and insignificant, as the regressions in Table 4 reveal: in columns (5) and (6) we report the results of two regressions with actual output as the dependent variable. The Peer treatment dummy has a significant negative coefficient, capturing the fact that performance is higher in every stage in Objective compared to Peer. One possible explanation for this is that performance determines the payment for participants in the former, but not in the latter treatment. However, the difference in performance between treatments does not vary significantly by incentive scheme (as seen by the insignificant interaction terms). In terms of our controls, the only variable that does have an effect on performance is the wage level, with higher earners performing better in the experimental task on average. The above findings lead us to reject Hypothesis 3, concluding that introducing competitive and team incentives under the peer evaluation protocol does not lead to a further reduction in output compared to objective evaluation.

Result 3: Performance is lower in every stage in the peer evaluation compared to the objective evaluation treatment. There is no change in the reduction in performance as a result of introducing competitive or team incentives. This leads us to reject Hypothesis 3.

\section{Concluding remarks}

The aim of this study has been to examine experimentally how dishonest behavior in the form of misreporting the performance of another participant reacts to incentives in the form of different compensation schemes. Using a sample of professional internal auditors recruited during two large conferences of the German Institute of Internal Audit, we have shown that individuals respond to changes in incentives in the predicted way: on average, they underreport each other's performance under a competitive compensation scheme and over-report it under a team-based compensation scheme. These findings complement the existing literature and draw attention to the potential perils associated with incentive-based compensation as it is often encountered in organizations. We have argued that professional auditors are particularly well suited for the study of these issues, given that they are employed in a sector where honest and objective behavior is among the central guiding principles, and also given that they typically face at least some combination of the type of incentives examined in our experiment.

Our results can make a number of important contributions to the profession of internal audit. First, we extend prior literature regarding the impairment of internal auditors' objectivity by demonstrating that the compensation scheme and personal economic interest directly effects the performance and reporting of internal auditors. Extending prior work by Omar and Stewart (2015) and Schneider (2003), we examine how internal auditors' objectivity reacts to economic incentives in the form of a tournament environment with the possibility of sabotage effects and an environment with team-based incentives. Given that the majority of companies use performance-based compensation schemes, our results identify potential risks of this approach. We expand the understanding of internal auditors' objectivity with regard to tournament environments and question if an MTG arrangement, as a typical 
example of a real-life tournament among internal auditors, strengthens or threatens their objectivity. Our findings suggest that, when internal auditors always see themselves in an MTG-induced tournament situation, their unbiased judgments and independent and objective audit and reporting are compromised. Further exploration of potential compensation schemes that avoid these negative effects is a promising avenue for future research.

At the same time, certain limitations should be acknowledged. While we view the sample of participating professionals as a strength of our study, we are not claiming to have replicated their working environment or studied them under realistic circumstances. For instance, it has been pointed out to us that the specific peer evaluation protocol employed in our experiment corresponds only very loosely to actual firm practices and that behavior might depend critically on the chosen real effort task. Hence, as with any lab (or lab in the field) experiment, the projection of our findings onto real behavior in organizations relies on the implicit assumption that responses to incentives are sufficiently generalizable from one environment to the other. Moreover, given the logistical constraints that we faced (running sessions in a limited amount of time and with relatively small samples), we were not able to investigate a number of further dimensions relevant to our questions of interest. Notably, one interesting treatment - in addition to objective and peer evaluation - would have been one in which participants are asked to evaluate their own performance in the task under different incentives. This would allow for a more comprehensive comparison with the literature, which often measures dishonesty by means of untruthful self-reports, and it would capture one more important dimension of employee behavior. 


\section{References}

Abbott, L. J., Daugherty, B., Parker, S. Peters, G. F, 2016. Internal audit quality and financial reporting quality: The joint importance of independence and competence. Journal of Accounting Research, 54(1), 3-40.

Abeler, J., Becker, A., Falk, A., 2014. Representative evidence on lying costs. Journal of Public Economics, 113, 96-104.

Araujo, F. A. d., Carbone, E., Conell-Price, L., Dunietz, M. W., Jaroszwicz, A., Landsman, R., Lamé, D., Vesterlund, L., Wang, S., Wilson, A. J., 2016. The slider task: An example of restricted inference on incentive effects. Journal of the Economic Science Association, 2(1), 1-12.

Baker, G. P., Jensen, M. C., Murphy, K. J., 1988. Compensation and incentives: Practice vs. theory. The journal of Finance, 43(3), 593-616.

Balafoutas, L., Lindner, F., Sutter, M., 2012. Sabotage in tournaments: evidence from a natural experiment. Kyklos, 65(4), 425-441.

Battigalli, P., Charness, G., Dufwenberg, M., 2013. Deception: The role of guilt. Journal of Economic Behavior \& Organization, 93, 227-232.

Battigalli, P., Dufwenberg, M., 2007. Guilt in games. American Economic Review, Papers and Proceedings, 97(2), 170-176.

Cadsby, C. B., Song, F., Tapon, F., 2010. Are you paying your employees to cheat? An experimental investigation. The BE Journal of Economic Analysis Policy, 10(1), 1-32.

Carpenter, J., Matthews, P. H., Schirm, J., 2010. Tournaments and office politics: Evidence from a real effort experiment. The American economic review, 100(1), 504-517.

Charness, G., Dufwenberg, M., 2006. Promises and partnership. Econometrica, 74, 15791601.

Charness, G., Kuhn, P., 2011. Lab labor: What can labor economists learn from the lab?. Handbook of labor economics, 4, 229-330.

Charness, G., Masclet, D., Villeval, M. C., 2014. The Dark Side of Competition for Status. Management Science, 60(1), 38-55.

Chen, K. P., 2003. Sabotage in promotion tournaments. Journal of Law, Economics, and Organization, 19(1), 119-140.

Chong, V. K., Eggleton, I. R., 2007. The impact of reliance on incentive-based compensation schemes, information asymmetry and organisational commitment on managerial performance. Management Accounting Research, 18(3), 312-342.

Chowdhury, S. M., Gürtler, O., 2015. Sabotage in contests: a survey. Public Choice, 164(1-2), $135-155$. 
Christ, M. H., Masli, A., Sharp, N. Y., Wood, D. A, 2015. Rotational internal audit programs and financial reporting quality: Do compensating controls help?. Accounting, Organizations and Society, 44, 37-59.

Cialdini, R. B., Reno, R. R., Kallgren, C. A., 1990. A focus theory of normative conduct: Recycling the concept of norms to reduce littering in public places. Journal of personality and social psychology, 58(6), 1015.

Cohn, A., Fehr, E., Maréchal, M. A., 2014. Business culture and dishonesty in the banking industry. Nature, 516(7529), 86-89.

Conrads, J., Irlenbusch, B., Rilke, R. M., Schielke, A., Walkowitz, G., 2014. Honesty in tournaments. Economics Letters, 123(1), 90-93.

Conrads, J., Irlenbusch, B., Rilke, R. M., Walkowitz, G., 2013. Lying and team incentives. Journal of Economic Psychology, 34, 1-7.

Danilov, A., Biemann, T., Kring, T., Sliwka, D., 2013. The dark side of team incentives: Experimental evidence on advice quality from financial service professionals. Journal of Economic Behavior \& Organization, 93, 266-272.

Dezoort, F. T., Houston, R. W., Reisch, J. T., 2000. Incentive-based compensation for internal auditors. Internal Auditor, 57(3), 42-42.

Dickins, D., O'Reilly, D., 2009. The qualifications and independence of internal auditors. Internal Auditing, 24(3), 14-21.

Eckartz, K., Kirchkamp, O., Schunk, D., 2012. How do incentives affect creativity?. CESifo Working Paper Series from CESifo Group Munich, No. 4049.

Erat, S., Gneezy, U., 2012. White lies. Management Science, 58(4), 723-733.

Eulerich, M., 2014. Die Interne Revision in Deutschland, Österreich und der Schweiz 2014. DIIR Verlag, Frankfurt 2014.

Faravelli, M., Friesen, L., Gangadharan, L., 2015. Selection, tournaments, and dishonesty. Journal of Economic Behavior Organization, 110, 160-175.

Fischbacher, U., Föllmi-Heusi, F., 2013. Lies in disguise - an experimental study on cheating. Journal of the European Economic Association, 11(3), 525-547.

Gino, F., Ayal, S., Ariely, D., 2009. Contagion and differentiation in unethical behavior the effect of one bad apple on the barrel. Psychological science, 20(3), 393-398.

Gino, F., Krupka, E., Weber, R., 2013. License to cheat: Voluntary regulation and ethical behavior. Management Science, 59(10), 2187-2203.

Gneezy, U., 2005. Deception: The role of consequences. The American Economic Review, 95(1), 384-394.

Gneezy, U., Rockenbach, B., Serra-Garcia, M., 2013. Measuring lying aversion. Journal of Economic Behavior \& Organization, 93, 293-300. 
Harbring, C., Irlenbusch, B., 2005. Incentives in tournaments with endogenous prize selection. Journal of Institutional and Theoretical Economics JITE, 161(4), 636-663.

Harbring, C., Irlenbusch, B., 2011. Sabotage in tournaments: Evidence from a laboratory experiment. Management Science, 57(4), 611-627.

Hoos, F., W. F. Messier, J. Smith, P. Tandy, 2014. The effects of serving two masters and using the internal audit function as a management training ground on internal auditors' objectivity. Unpublished paper, HEC Paris, and University of Nevada, Available at: http://papers.ssrn.com/sol3/papers.cfm?abstract_id=2358149.

IIA (Institute of Internal Auditors Research Foundation), 2016. International Professional Practices Framework (IPPF). Institute of Internal Auditors Research Foundation.

Irlenbusch, B., Villeval, M. C., 2015. Behavioral ethics: how psychology influenced economics and how economics might inform psychology?. Current Opinion in Psychology, 6, 87-92.

Kajackaite, A., Gneezy, U., 2015. Lying costs and incentives. UC San Diego Discussion Paper.

Keizer, K., Lindenberg, S., Steg, L., 2008. The spreading of disorder. Science, 322(5908), 1681-1685.

Kochetova-Kozloski, N., Messier Jr, W. F., 2011. Strategic analysis and auditor risk judgments. Auditing: A Journal of Practice Theory, 30(4), 149-171.

Lazear, E. P., 1989. Pay equality and industrial politics. Journal of political economy, 97(3), 561-580.

Mazar, N., Amir, O., Ariely, D., 2008. The dishonesty of honest people: A theory of selfconcept maintenance. Journal of marketing research, 45(6), 633-644.

Messier Jr, W. F., Reynolds, J. K., Simon, C. A., Wood, D. A, 2011. The effect of using the internal audit function as a management training ground on the external auditor's reliance decision. The Accounting Review, 86(6), 2131-2154.

Mutchler, J. F., 2003. Independence and objectivity: A framework for internal auditors', in Baily. A. D., Gramling, A. A., Ramamoorti, S. (eds), Research Opportunities in Internal Auditing, Altamonte Springs, FL: The Institute of Internal Auditors Research Foundation, 231-68.

Omar, H.B.M.H., Stewart, J., 2015. The effect of incentive-based compensation on internal auditors' perceptions of objectivity. International Journal of Auditing, 19(1), 37-52.

Rosaz, J., \& Villeval, M.C., 2012. Lies and biased evaluation: A real-effort experiment. Journal of Economic Behavior \& Organization, 84(2), 537-549.

Rose, A. M., Rose, J. M., Norman, C. S., 2013. Is the objectivity of internal audit compromised when the internal audit function is a management training ground? Accounting Finance, 53(4), 1001-1019. 
Schneider, A., 2003. An examination of whether incentive compensation and stock ownership affect internal auditor objectivity. Journal of Managerial Issues, 15(4), 486-497.

Schweitzer, M. E., Ordóñez, L., Douma, B., 2004. Goal setting as a motivator of unethical behavior. Academy of Management Journal, 47(3), 422-432.

Schwieren, C., Weichselbaumer, D., 2010 Does competition enhance performance or cheating? A laboratory experiment. Journal of Economic Psychology, 31(3), 241-253.

Shalvi, S., Dana, J., Handgraaf, M. J., De Dreu, C. K., 2011. Justified ethicality: Observing desired counterfactuals modifies ethical perceptions and behavior. Organizational Behavior and Human Decision Processes, 115(2), 181-190.

Skinner, D. J., Srinivasan, S., 2012. Audit quality and auditor reputation: Evidence from Japan. The Accounting Review, 87(5), 1737-1765.

Sutter, M., 2009. Individual behavior and group membership: Comment. The American Economic Review, 99(5), 2247-2257.

Takahashi, H., Shen, J., Ogawa, K., 2016. An experimental examination of compensation schemes and level of effort in differentiated tasks. Journal of Behavioral and Experimental Economics, 61, 12-19.

Watts, R. L., Zimmerman, J. L., 1990. Positive accounting theory: A ten year perspective. The Accounting Review, 65(1), 131-56.

Wiltermuth, S. S., 2011. Cheating more when the spoils are split. Organizational Behavior and Human Decision Processes, 115(2), 157-168. 


\section{Tables and Figures}

Table 1: Background information on participants

\begin{tabular}{|c|c|c|c|c|}
\hline Treatment: & Both & Objective & Peer & $\mathrm{p}$ value \\
\hline Age & $42.40(8.67)$ & $42.09(9.32)$ & $42.69(8.11)$ & 0.79 \\
\hline$\%$ Female & 34.74 & 33.33 & 36.00 & 0.83 \\
\hline Experience as IA in years & $11.09(6.46)$ & $10(6.71)$ & $12.08(6.12)$ & 0.07 \\
\hline$\%$ variable wage component & 76.60 & 68.89 & 83.67 & 0.14 \\
\hline $\begin{array}{l}\% \text { variable component depends } \\
\text { on personal performance }\end{array}$ & 62.11 & 55.56 & 68.00 & 0.29 \\
\hline $\begin{array}{l}\% \text { variable component depends } \\
\text { on department performance }\end{array}$ & 12.63 & 11.11 & 14.00 & 0.76 \\
\hline $\begin{array}{l}\% \text { variable component depends } \\
\text { on company performance }\end{array}$ & 60.00 & 48.89 & 70.00 & 0.06 \\
\hline$\%$ working in public sector & 11.58 & 13.33 & 10.00 & 0.75 \\
\hline$\%$ working in finance sector & 37.89 & 28.89 & 46.00 & 0.10 \\
\hline$\%$ Master or $\mathrm{PhD}$ degree & 18.95 & 17.78 & 20.00 & 0.80 \\
\hline $\begin{array}{l}\% \text { having at least one person } \\
\text { working for them }\end{array}$ & 36.84 & 42.22 & 32.22 & 0.40 \\
\hline$\%$ who are in MTG & 30.77 & 28.89 & 32.61 & 0.82 \\
\hline risk attitude & $5.21(2.20)$ & $5.18(2.06)$ & $5.24(2.34)$ & 0.76 \\
\hline competitive perception & $2.90(1.23)$ & $3.04(1.21)$ & $2.78(1.25)$ & 0.26 \\
\hline
\end{tabular}

Notes: Table presents mean values (with standard deviations in parentheses) or percentages. $\mathrm{p}$ values testing equality across treatments, based on Fisher's exact tests, except for variables age, experience, risk attitudes and competitive perception (Mann-Whitney U tests). 
Table 2: Mean actual and reported performance (standard deviations in parentheses) Panel (a): Treatment Peer

\begin{tabular}{lccc}
\hline & Individual & Competitive & Collective \\
\hline \multirow{2}{*}{ Actual points } & 5.96 & 5.87 & 6.16 \\
& $(1.63)$ & $(1.89)$ & $(2.03)$ \\
Reported points & 6.07 & 4.57 & 7.17 \\
& $(2.08)$ & $(3.99)$ & $(7.17)$ \\
Difference (reported-actual) & 0.11 & -1.3 & 1.01 \\
& $(1.23)$ & $(3.63)$ & $(2.10)$ \\
\hline
\end{tabular}

Panel (b): Treatment Objective

\begin{tabular}{lccc}
\hline & Individual & Competitive & Collective \\
\hline \multirow{2}{*}{ Actual points } & 6.73 & 6.65 & 6.95 \\
& $(2.26)$ & $(2.63)$ & $(1.77)$ \\
Reported points & 6.75 & 6.52 & 6.98 \\
& $(2.08)$ & $(3.40)$ & $(2.17)$ \\
Difference (reported-actual) & 0.02 & -0.13 & -0.05 \\
& $(1.08)$ & $(1.17)$ & $(0.70)$ \\
\hline
\end{tabular}

Table 3: Share of (un)truthful reports, by stage and treatment

Panel (a): Treatment Peer (number of reports, out of 50)

\begin{tabular}{lccc}
\hline & Individual & Competitive & Team \\
\hline untruthful & 7 & 13 & 15 \\
truthful & 43 & 37 & 35 \\
\hline
\end{tabular}

Panel (b): Treatment Objective (number of reports, out of 45)

\begin{tabular}{lccc}
\hline & Individual & Competitive & Team \\
\hline untruthful & 12 & 7 & 5 \\
truthful & 33 & 38 & 38 \\
\hline
\end{tabular}


Table 4: Regression analysis

\begin{tabular}{|c|c|c|c|c|c|c|}
\hline Dep. variable & $\begin{array}{c}(1) \\
\text { reported } \\
\text { - actual } \\
\text { points }\end{array}$ & $\begin{array}{c}(2) \\
\text { reported } \\
- \text { actual } \\
\text { points }\end{array}$ & $\begin{array}{c}\text { (3) } \\
\text { reported - } \\
\text { actual } \\
\text { points }\end{array}$ & $\begin{array}{c}\text { (4) } \\
\text { reported - } \\
\text { actual } \\
\text { points }\end{array}$ & $\begin{array}{c}(5) \\
\text { actual } \\
\text { points }\end{array}$ & $\begin{array}{c}\text { (6) } \\
\text { actual } \\
\text { points }\end{array}$ \\
\hline Treatment & Both & Both & Objective & Peer & Both & Both \\
\hline other perf. & $\begin{array}{l}-0.132^{*} \\
(0.073)\end{array}$ & $\begin{array}{l}-0.131^{*} \\
(0.074)\end{array}$ & $\begin{array}{c}-0.077 \\
(0.067)\end{array}$ & $\begin{array}{l}-0.129 \\
(0.182)\end{array}$ & & \\
\hline own perf. & $\begin{array}{c}0.092 \\
(0.063)\end{array}$ & $\begin{array}{c}0.159^{*} \\
(0.081)\end{array}$ & $\begin{array}{c}0.008 \\
(0.059)\end{array}$ & $\begin{array}{c}0.398^{*} \\
(0.205)\end{array}$ & & \\
\hline comp. stage & $\begin{array}{l}-0.159 \\
(0.206)\end{array}$ & $\begin{array}{c}-0.254 \\
(0.243)\end{array}$ & $\begin{array}{l}-0.222 \\
(0.232)\end{array}$ & $\begin{array}{c}-1.662^{* * *} \\
(0.615)\end{array}$ & $\begin{array}{c}-0.078 \\
(0.391)\end{array}$ & $\begin{array}{c}0.141 \\
(0.392)\end{array}$ \\
\hline team stage & $\begin{array}{c}-0.291 \\
(0.207)\end{array}$ & $\begin{array}{l}-0.280 \\
(0.217)\end{array}$ & $\begin{array}{l}-0.253 \\
(0.221)\end{array}$ & $\begin{array}{l}1.004^{* *} \\
(0.391)\end{array}$ & $\begin{array}{c}0.222 \\
(0.266)\end{array}$ & $\begin{array}{c}0.269 \\
(0.306)\end{array}$ \\
\hline peer reporting & $\begin{array}{c}0.056 \\
(0.221)\end{array}$ & $\begin{array}{c}0.035 \\
(0.280)\end{array}$ & & & $\begin{array}{l}-0.773^{*} \\
(0.409)\end{array}$ & $\begin{array}{l}-0.877^{*} \\
(0.454)\end{array}$ \\
\hline comp.x peer & $\begin{array}{c}-1.255^{* *} \\
(0.537)\end{array}$ & $\begin{array}{l}-1.402^{* *} \\
(0.656)\end{array}$ & & & $\begin{array}{l}-0.012 \\
(0.483)\end{array}$ & $\begin{array}{c}-0.116 \\
(0.516)\end{array}$ \\
\hline team $x$ peer & $\begin{array}{l}1.199^{* * *} \\
(0.358)\end{array}$ & $\begin{array}{l}1.344^{* * *} \\
(0.423)\end{array}$ & & & $\begin{array}{c}-0.022 \\
(0.381)\end{array}$ & $\begin{array}{l}-0.019 \\
(0.438)\end{array}$ \\
\hline female & & $\begin{array}{l}0.413^{*} \\
(0.237)\end{array}$ & $\begin{array}{c}0.173 \\
(0.317)\end{array}$ & $\begin{array}{c}0.289 \\
(0.383)\end{array}$ & & $\begin{array}{l}-0.024 \\
(0.406)\end{array}$ \\
\hline$M T G$ & & $\begin{array}{c}-0.016 \\
(0.374)\end{array}$ & $\begin{array}{l}-0.461 \\
(0.402)\end{array}$ & $\begin{array}{c}0.928 \\
(0.839)\end{array}$ & & $\begin{array}{c}-0.538 \\
(0.412)\end{array}$ \\
\hline risk measure & & $\begin{array}{c}0.088 \\
(0.086)\end{array}$ & $\begin{array}{c}0.066 \\
(0.078)\end{array}$ & $\begin{array}{c}0.057 \\
(0.135)\end{array}$ & & $\begin{array}{c}0.019 \\
(0.102)\end{array}$ \\
\hline comp. measure & & $\begin{array}{c}0.244 \\
(0.168)\end{array}$ & $\begin{array}{c}0.006 \\
(0.132)\end{array}$ & $\begin{array}{l}0.669^{*} \\
(0.354)\end{array}$ & & $\begin{array}{l}-0.255 \\
(0.161)\end{array}$ \\
\hline variable wage & & $\begin{array}{c}-0.001 \\
(0.243)\end{array}$ & $\begin{array}{c}0.250 \\
(0.310)\end{array}$ & $\begin{array}{c}0.239 \\
(0.398)\end{array}$ & & $\begin{array}{c}0.039 \\
(0.494)\end{array}$ \\
\hline wage level & & $\begin{array}{c}0.031 \\
(0.114)\end{array}$ & $\begin{array}{c}0.208 \\
(0.127)\end{array}$ & $\begin{array}{l}-0.368^{*} \\
(0.217)\end{array}$ & & $\begin{array}{l}0.286^{* *} \\
(0.139)\end{array}$ \\
\hline constant & $\begin{array}{c}0.295 \\
(0.620)\end{array}$ & $\begin{array}{l}-1.496 \\
(1.135)\end{array}$ & $\begin{array}{l}-0.478 \\
(0.912)\end{array}$ & $\begin{array}{l}-3.284 \\
(2.658)\end{array}$ & $\begin{array}{l}6.733^{* * *} \\
(0.337)\end{array}$ & $\begin{array}{l}6.642^{* * *} \\
(0.920)\end{array}$ \\
\hline$N$ & 285 & 237 & 117 & 120 & 285 & 237 \\
\hline
\end{tabular}

Notes: Ordinary least squares regressions. Standard errors in parentheses, clustered by participant. All regression specifications include participant random effects. ${ }^{*} p<0.10,{ }^{* *} p<0.05,{ }^{* * *} p<0.01$ 
Figure 1: Distribution of actual points, reported points and (non-zero) differences between reported and actual points, by treatment and stage

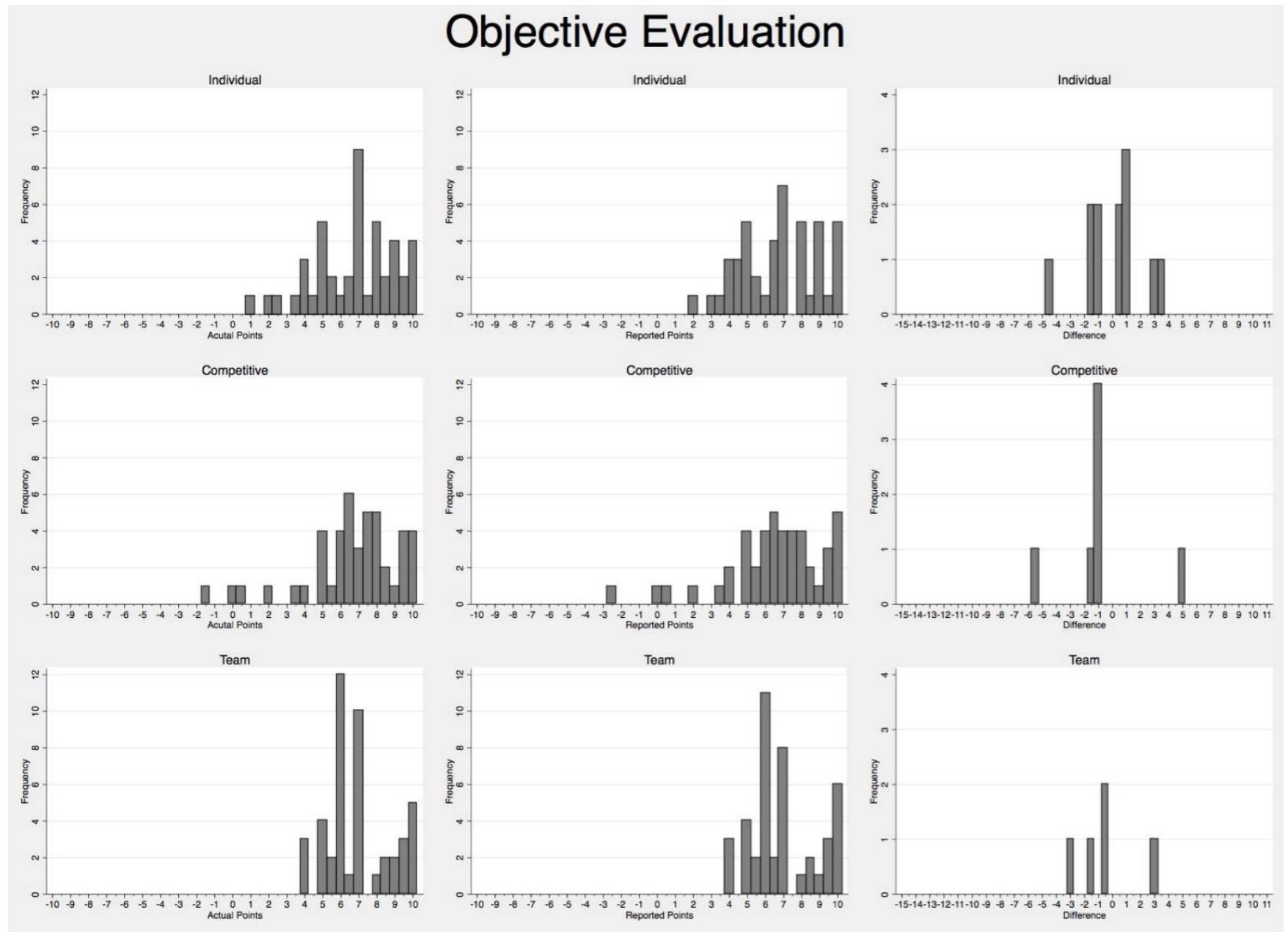




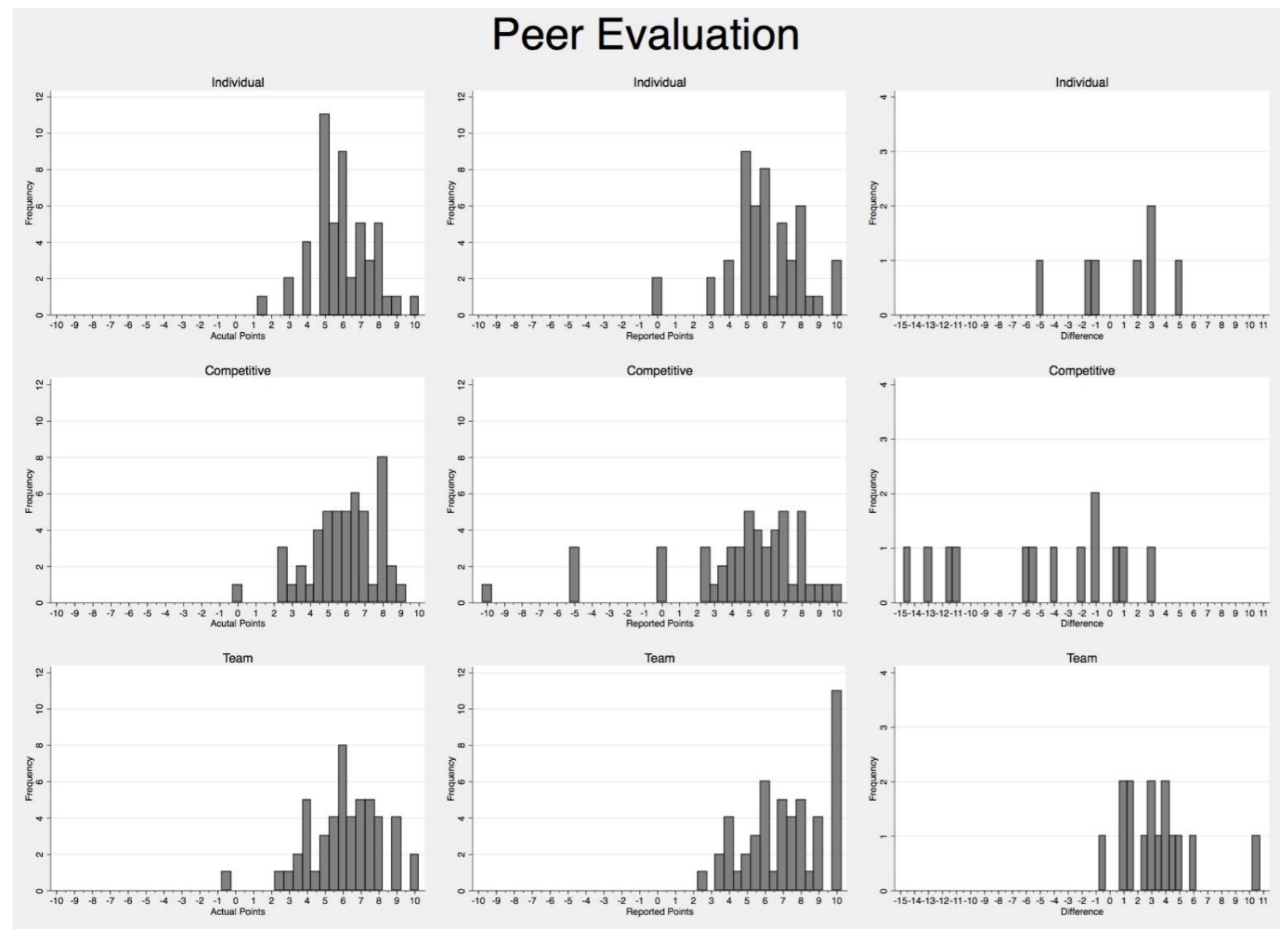

Notes: The first row in each graph corresponds to the individual stage, the second row to the competitive stage and the third row to the team stage. The first column in each row shows actual points, the second column shows reported points, and the third column shows the difference, (reported points - actual points). For ease of exposition, in the third column (differences) we omit values of zero. 


\section{Appendix}

Figure A.1: Example of the real-effort task

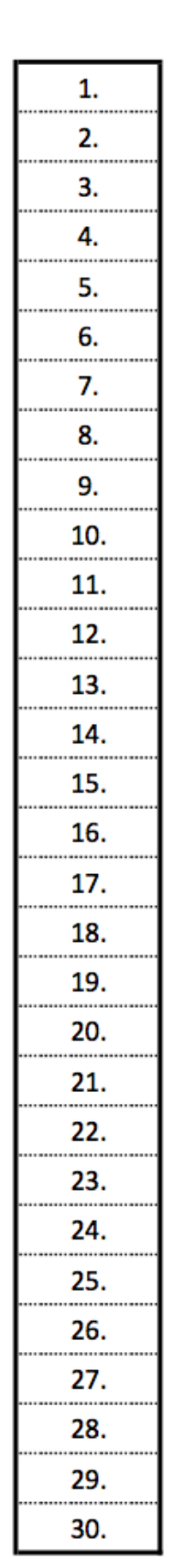

\begin{tabular}{|c|c|c|}
\hline Zahl 1 & Zahl 2 & Zahl 3 \\
\hline 56 & 61 & 15 \\
\hline 79 & 20 & 94 \\
\hline 16 & 77 & 28 \\
\hline 55 & 60 & 42 \\
\hline 65 & 55 & 10 \\
\hline 20 & 67 & 36 \\
\hline 89 & 99 & 65 \\
\hline 35 & 77 & 98 \\
\hline 43 & 20 & 59 \\
\hline 82 & 51 & 33 \\
\hline 39 & 47 & 48 \\
\hline 23 & 30 & 47 \\
\hline 39 & 11 & 79 \\
\hline 15 & 39 & 33 \\
\hline 52 & 28 & 97 \\
\hline 41 & 60 & 19 \\
\hline 62 & 12 & 46 \\
\hline 20 & 37 & 88 \\
\hline 40 & 50 & 84 \\
\hline 45 & 55 & 12 \\
\hline 82 & 90 & 24 \\
\hline 79 & 45 & 74 \\
\hline 68 & 63 & 40 \\
\hline 66 & 24 & 96 \\
\hline 33 & 77 & 24 \\
\hline 17 & 64 & 70 \\
\hline 53 & 35 & 88 \\
\hline 34 & 15 & 16 \\
\hline 51 & 48 & 46 \\
\hline 85 & 11 & 36 \\
\hline
\end{tabular}

\begin{tabular}{|c|c|}
\hline Ergebnis & Falsch? \\
\hline 132 & \\
\hline 192 & \\
\hline 121 & \\
\hline 157 & \\
\hline 130 & \\
\hline 113 & \\
\hline 253 & \\
\hline 120 & \\
\hline 122 & \\
\hline 164 & \\
\hline 134 & \\
\hline 100 & \\
\hline 130 & \\
\hline 87 & \\
\hline 177 & \\
\hline 120 & \\
\hline 140 & \\
\hline 145 & \\
\hline 174 & \\
\hline 112 & \\
\hline 195 & \\
\hline 189 & \\
\hline 171 & \\
\hline 186 & \\
\hline 134 & \\
\hline 151 & \\
\hline 166 & \\
\hline 65 & \\
\hline 144 & \\
\hline 132 & \\
\hline
\end{tabular}

Gesamtpunkteanzahl 
(1) (2)

Dep. variable ${ }^{\#}$

Relative

Relative

misreporting

misreporting

\begin{tabular}{|c|c|c|}
\hline other perf. & $\begin{array}{l}-0.929 \\
(0.828)\end{array}$ & $\begin{array}{c}-0.952 \\
(0.961)\end{array}$ \\
\hline own perf. & $\begin{array}{c}0.823 \\
(0.831)\end{array}$ & $\begin{array}{c}1.433 \\
(1.001)\end{array}$ \\
\hline comp. stage & $\begin{array}{l}-3.897 \\
(4.878)\end{array}$ & $\begin{array}{c}-5.034 \\
(5.534)\end{array}$ \\
\hline team stage & $\begin{array}{l}-4.562 \\
(4.884)\end{array}$ & $\begin{array}{l}-4.855 \\
(5.539)\end{array}$ \\
\hline peer reporting & $\begin{array}{c}0.343 \\
(5.533)\end{array}$ & $\begin{array}{l}-0.542 \\
(6.392)\end{array}$ \\
\hline comp. x peer & $\begin{array}{l}-6.195 \\
(6.722)\end{array}$ & $\begin{array}{l}-6.024 \\
(7.771)\end{array}$ \\
\hline team $x$ peer & $\begin{array}{c}22.516^{* * *} \\
(6.735)\end{array}$ & $\begin{array}{c}25.820^{* * *} \\
(7.788)\end{array}$ \\
\hline female & & $\begin{array}{c}2.743 \\
(4.962)\end{array}$ \\
\hline$M T G$ & & $\begin{array}{l}-7.251 \\
(5.607)\end{array}$ \\
\hline risk measure & & $\begin{array}{c}0.379 \\
(1.175)\end{array}$ \\
\hline comp.measure & & $\begin{array}{c}0.051 \\
(2.300)\end{array}$ \\
\hline variable wage & & $\begin{array}{c}4.723 \\
(5.773)\end{array}$ \\
\hline wage level & & $\begin{array}{c}1.383 \\
(1.717)\end{array}$ \\
\hline constant & $\begin{array}{c}5.546 \\
(8.716)\end{array}$ & $\begin{array}{c}-5.353 \\
(16.548)\end{array}$ \\
\hline$N$ & 285 & 237 \\
\hline comp. stage + comp. $x$ peer & $-10.092 * * *$ & $-11.058 * * *$ \\
\hline team stage + team $x$ peer & $17.954 * * *$ & $19.796 * * *$ \\
\hline
\end{tabular}

Notes: Tobit regressions. Standard errors in parentheses. All regression specifications include participant random effects. ${ }^{* * *} p<0.01$. The last two columns report $p$ values from $\chi^{2}$ tests on the restriction that the respective joint coefficient is equal to zero.

\# Dependent variable is relative misreporting in \%, defined as the difference between reported and actual points divided by the maximum possible difference in each observation and multiplied by 100 . 
University of Innsbruck - Working Papers in Economics and Statistics Recent Papers can be accessed on the following webpage:

http://eeecon.uibk.ac.at/wopec/

2017-06 Loukas Balafoutas, Simon Czermak, Marc Eulerich, Helena Fornwagner: Incentives for dishonesty: An experimental study with internal auditors

2017-05 Nikolaus Umlauf, Nadja Klein, Achim Zeileis: BAMLSS: Bayesian additive models for location, scale and shape (and beyond)

2017-04 Martin Halla, Susanne Pech, Martina Zweimüller: The effect of statutory sick-pay on workers' labor supply and subsequent health

2017-03 Franz Buscha, Daniel Müller, Lionel Page: Can a common currency foster a shared social identity across different nations? The case of the Euro.

2017-02 Daniel Müller: The anatomy of distributional preferences with group identity

2017-01 Wolfgang Frimmel, Martin Halla, Jörg Paetzold: The intergenerational causal effect of tax evasion: Evidence from the commuter tax allowance in Austria

2016-33 Alexander Razen, Stefan Lang, Judith Santer: Estimation of spatially correlated random scaling factors based on Markov random field priors

2016-32 Meike Köhler, Nikolaus Umlauf, Andreas Beyerlein, Christiane Winkler, Anette-Gabriele Ziegler, Sonja Greven: Flexible Bayesian additive joint models with an application to type 1 diabetes research

2016-31 Markus Dabernig, Georg J. Mayr, Jakob W. Messner, Achim Zeileis: Simultaneous ensemble post-processing for multiple lead times with standardized anomalies

2016-30 Alexander Razen, Stefan Lang: Random scaling factors in Bayesian distributional regression models with an application to real estate data

2016-29 Glenn Dutcher, Daniela Glätzle-Rützler, Dmitry Ryvkin: Don't hate the player, hate the game: Uncovering the foundations of cheating in contests

2016-28 Manuel Gebetsberger, Jakob W. Messner, Georg J. Mayr, Achim Zeileis: Tricks for improving non-homogeneous regression for probabilistic precipitation forecasts: Perfect predictions, heavy tails, and link functions

2016-27 Michael Razen, Matthias Stefan: Greed: Taking a deadly sin to the lab 
2016-26 Florian Wickelmaier, Achim Zeileis: Using recursive partitioning to account for parameter heterogeneity in multinomial processing tree models

2016-25 Michel Philipp, Carolin Strobl, Jimmy de la Torre, Achim Zeileis: On the estimation of standard errors in cognitive diagnosis models

2016-24 Florian Lindner, Julia Rose: No need for more time: Intertemporal allocation decisions under time pressure

2016-23 Christoph Eder, Martin Halla: The long-lasting shadow of the allied occupation of Austria on its spatial equilibrium

2016-22 Christoph Eder: Missing men: World War II casualties and structural change

2016-21 Reto Stauffer, Jakob Messner, Georg J. Mayr, Nikolaus Umlauf, Achim Zeileis: Ensemble post-processing of daily precipitation sums over complex terrain using censored high-resolution standardized anomalies published in Monthly Weather Review

2016-20 Christina Bannier, Eberhard Feess, Natalie Packham, Markus Walzl: Incentive schemes, private information and the double-edged role of competition for agents

2016-19 Martin Geiger, Richard Hule: Correlation and coordination risk

2016-18 Yola Engler, Rudolf Kerschbamer, Lionel Page: Why did he do that? Using counterfactuals to study the effect of intentions in extensive form games

2016-17 Yola Engler, Rudolf Kerschbamer, Lionel Page: Guilt-averse or reciprocal? Looking at behavioural motivations in the trust game

2016-16 Esther Blanco, Tobias Haller, James M. Walker: Provision of public goods: Unconditional and conditional donations from outsiders

2016-15 Achim Zeileis, Christoph Leitner, Kurt Hornik: Predictive bookmaker consensus model for the UEFA Euro 2016

2016-14 Martin Halla, Harald Mayr, Gerald J. Pruckner, Pilar García-Gómez: Cutting fertility? The effect of Cesarean deliveries on subsequent fertility and maternal labor supply

2016-13 Wolfgang Frimmel, Martin Halla, Rudolf Winter-Ebmer: How does parental divorce affect children's long-term outcomes?

2016-12 Michael Kirchler, Stefan Palan: Immaterial and monetary gifts in economic transactions. Evidence from the field

2016-11 Michel Philipp, Achim Zeileis, Carolin Strobl: A toolkit for stability assessment of tree-based learners 
2016-10 Loukas Balafoutas, Brent J. Davis, Matthias Sutter: Affirmative action or just discrimination? A study on the endogenous emergence of quotas published in Journal of Economic Behavior and Organization

2016-09 Loukas Balafoutas, Helena Fornwagner: The limits of guilt

2016-08 Markus Dabernig, Georg J. Mayr, Jakob W. Messner, Achim Zeileis: Spatial ensemble post-processing with standardized anomalies

2016-07 Reto Stauffer, Jakob W. Messner, Georg J. Mayr, Nikolaus Umlauf, Achim Zeileis: Spatio-temporal precipitation climatology over complex terrain using a censored additive regression model

2016-06 Michael Razen, Jürgen Huber, Michael Kirchler: Cash inflow and trading horizon in asset markets

2016-05 Ting Wang, Carolin Strobl, Achim Zeileis, Edgar C. Merkle: Scorebased tests of differential item functioning in the two-parameter model

2016-04 Jakob W. Messner, Georg J. Mayr, Achim Zeileis: Non-homogeneous boosting for predictor selection in ensemble post-processing

2016-03 Dietmar Fehr, Matthias Sutter: Gossip and the efficiency of interactions

2016-02 Michael Kirchler, Florian Lindner, Utz Weitzel: Rankings and risktaking in the finance industry

2016-01 Sibylle Puntscher, Janette Walde, Gottfried Tappeiner: Do methodical traps lead to wrong development strategies for welfare? A multilevel approach considering heterogeneity across industrialized and developing countries 


\title{
University of Innsbruck
}

\section{Working Papers in Economics and Statistics}

2017-06

Loukas Balafoutas, Simon Czermak, Marc Eulerich, Helena Fornwagner

Incentives for dishonesty: An experimental study with internal auditors

\begin{abstract}
This study examines experimentally how dishonest behavior in the form of misreporting others' performance depends on the nature of provided incentives. We conduct a "lab in the field" experiment with internal auditors during two large conferences in Germany and evaluate their performance and objectivity, measured as the extent to which they truthfully report the performance of other participants a real-effort task. It has been suggested in the literature that incentive-pay compensation for auditors has the potential to lead to dishonest behavior on their part, for instance when their payoff depends on the performance of the unit that they are auditing. We vary incentives in the experiment from individual (piece rate) to competitive (tournament against another auditor) and collective (based on performance within a team). In line with our hypotheses, we find that incentive-based compensation increases dishonest behavior among internal auditors: competitive incentives lead to under-reporting of other participants' performance, while collective incentives lead to over-reporting of performance.
\end{abstract}

ISSN 1993-4378 (Print)

ISSN 1993-6885 (Online) 